\title{
Enhancing Tensile Ductility of a Particulate-Reinforced Aluminum MMC by Lamination with Mg-9\% Li Alloy
}

\author{
C.K. Syn, D.R. Lesuer, and O.D. Sherby
}

May 1995

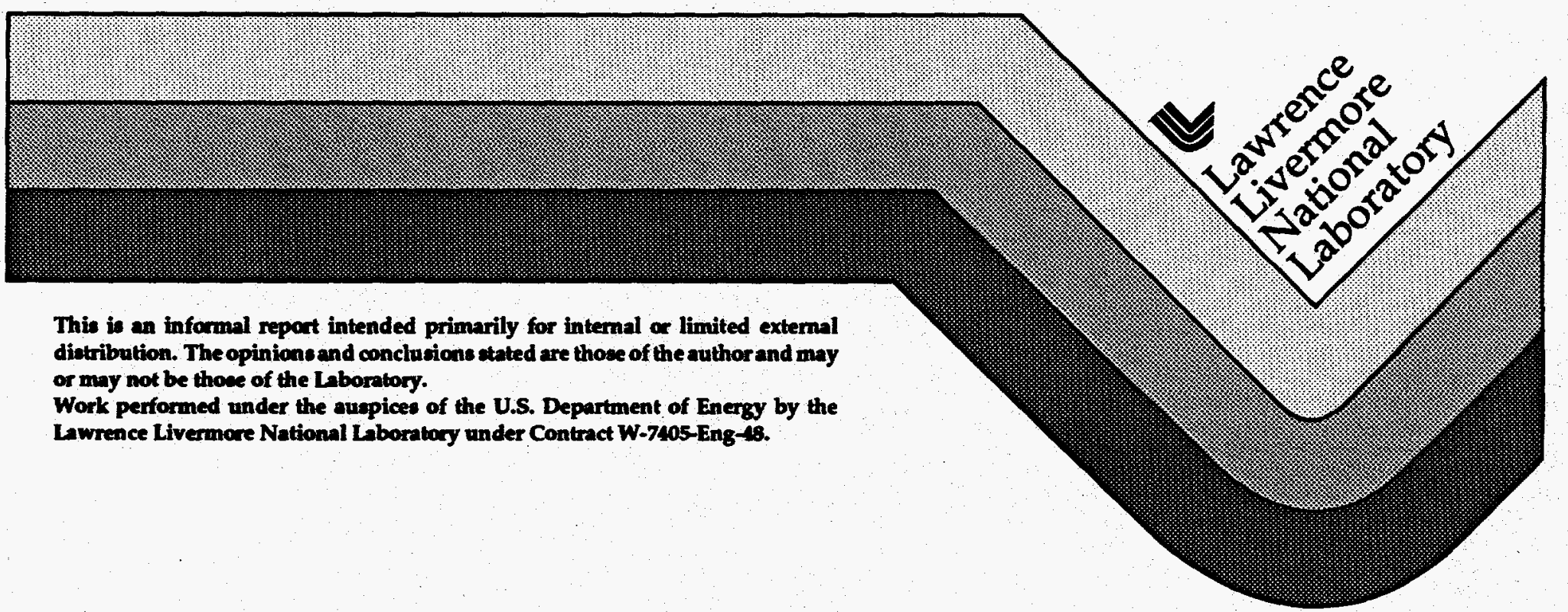




\section{DISCLAIMER}

This document was prepared as an account of work sponsored by an agency of the United States Government. Neither the United States Government nor the University of California nor any of their employees, makes any warranty, express or implied, or assumes any legal liability or responsibility for the accuracy, completeness, or usefulness of any information, apparatus, product, or process disclosed, or represents that its use would not infringe privately owned rights. Reference herein to any specific commercial products, process, or service by trade name, trademark, manufacturer, or otherwise, does not necesserily constitute or imply its endorsement, recommendation, or favoring by the United States Government or the University of California. The views and opinions of authors expressed herein do not necessarily state or reflect those of the United States Government or the University of California, and shall not be used for advertising or product endorsement purposes.

This report has been reproduced directly from the best available copy.

Available to DOE and DOE contractors from the Office of Scientific and Technical Information P.O. Box 62, Oak Ridge, TN 37831

Prices avaitable from (615) 576-8401, FTS 626-8401

Available to the public from the National Technical Information Service

US. Department of Commerce 5285 Port Royal Rd.,

Springfield, VA 22161 


\section{DISCLAIMER}

Portions of this document may be illegible in electronic image products. Images are produced from the best available original document. 


\title{
Enhancing Tensile Ductility of \\ a Particulate-Reinforced Aluminum MMC by \\ Lamination with Mg-9\%Li Alloy*
}

C. K. Syn+, D. R. Lesuert and O. D. Sherbyt

+ Lawrence Livermore National Laboratory, Livermore, CA 94550

tDep't of Materials Science and Engineering, Stanford University

Stanford, CA 94305

\begin{abstract}
A laminated metal composite has been made by press bonding alternating layers of a particulate-reinforced aluminum MMC, $6090 / \mathrm{SiC} / 25 \mathrm{p}$, and a $\mathrm{Mg}-9 \% \mathrm{Li}$ alloy. The mechanical properties including tensile ductility were evaluated. The tensile ductility of the Al MMC was found to increase from $3.5 \%$ to $11.5 \%$. In contrast to other laminates based on ultrahigh carbon steel, the laminate of this study and other AI MMC laminates exhibited tensile yield strengths that did not follow the rule of averages. This is attributed to interlayer reaction products developed during processing of the Al MMC laminates.
\end{abstract}

\section{MASTER}




\section{INTRODUCTION}

Metal Matrix Composites (MMC) have been studied extensively in recent years. The aluminum MMC materials have been shown to be particularly attractive for structural applications because of their high specific strength at low and high temperatures, and their high specific elastic stiffness. The room temperature ductility of typical aluminum MMCs reinforced with particles, however, is not high, and ranges from 2 to $5 \%$ elongation[1]. These low ductilities are related to the presence of the large volume fraction of hard ceramic phase ( $\mathrm{SiC}$ or $\mathrm{Al}_{2} \mathrm{O}_{3}$ ), typically 20 volume percent, which contributes to premature fracture from particle cracking and particle-matrix decohesion.

This paper investigates the tensile ductility of an aluminum MMC (6090/SiC/25p) when laminated with a tensile ductile lowdensity Mg-9\%Li alloy. Previous studies have shown that lamination can enhance the ductility of MMCs. For example, the tensile ductility of a $6061 / \mathrm{SiC} / 25 \mathrm{p} \mathrm{MMC}$ was increased from about $4 \%$ elongation to about $15 \%$ elongation by lamination with a solid solution aluminum alloy, $\mathrm{Al}-5182[2]$. Another example is that of an ultrahigh carbon steel (UHCS) laminated with brass. A laminate consisting of 
alternating thin layers (about $50 \mu \mathrm{m}$ thick) of UHCS and brass was shown to have a tensile elongation of $60 \%$, whereas the UHCS alone exhibits only about $20 \%$ elongation[3]. This tensile ductility enhancement by lamination with brass is a result of the prevention of flow localization, a precursor to failure, in the less ductile UHCS layer.

\section{MATERIALS AND PROCESSING}

The aluminum MMC material selected was 6090 aluminum containing 25 vol. $\%$ SiC particles, designated as $6090 / \mathrm{SiC} / 25 \mathrm{p}$. The material was received in the form of a sheet, $3 \mathrm{~mm}$ thick. Its tensile elongation at room temperature is $3.5 \%$. The $\mathrm{Mg}$-Li alloy contained 9 wt\% lithium, and consisted of two phases, hexagonal-close-packed (hcp), $\alpha$, and body-centered-cubic (bcc), $\beta$. The $\mathrm{Mg}-\mathrm{Li}$ alloy was processed into sheet, $3 \mathrm{~mm}$ thick, by warm rolling the original casting. Its tensile ductility at room temperature was determined to be about $30 \%$ elongation.

Laminates of the two materials were prepared by a press-bonding procedure. The sheet of each material, in the form of discs, was 
cleaned by a dilute solution of nitric and hydrochloric acid, and in the case of the Mg-Li alloy, it was further cleaned by glass-beading. The stacking of the materials was done in a special way and is shown in Fig. 1. The Al MMC discs were made larger than the Mg-Li alloy discs. The empty space between the two materials was filled with hollow rings of Al 5182 alloy (a solid solution aluminum alloy containing magnesium). The addition of the 5182 rings was to restrain the flow of the soft $\mathrm{Mg}-\mathrm{Li}$ alloy at the temperature of pressing $\left(450^{\circ} \mathrm{C}\right)$. The $\mathrm{Mg}-\mathrm{Li}$ alloy is about ten times weaker than the aluminum MMC at this temperature $\left(450^{\circ} \mathrm{C}\right)[4,5]$. As can be seen in Fig. 1, additional material, consisting of five alternating layers of the two aluminum alloys, was added to each end of the laminate stack. The purpose of the additional layers was to achieve a more uniform flow of the laminate, since the top and bottom layers are constrained during pressing by friction between these layers and the platens of the press. The total stack height was $40 \mathrm{~mm}$.

The stack was placed in a chamber assembled in a press. The chamber was evacuated and then filled with argon. The whole assembly was heated to $450^{\circ} \mathrm{C}$ which took about 30 minutes, and the pressing was started after 15 minutes of soaking. Two pressing speeds were used. One stack was pressed from $40 \mathrm{~mm}$ to $10 \mathrm{~mm}$ in 
10 minutes. The other stack was pressed by the same amount in 100 minutes. Fig. 2 shows a sectioned laminate which was made by pressing in 10 minutes. Uniform deformation of the $\mathrm{Mg}-\mathrm{Li}$ and aluminum MMC layers is seen to occur in the center portion of the pressed laminate. The outer edges, as well as the top and bottom layers, however, are seen to deform inhomogeneously.

\section{RESULTS AND DISCUSSION}

Microstructure

Fig. 3 is a photomicrograph of the center section in the pressed laminate shown in Fig. 2. The layers of each material are seen to be of equal thickness, attesting to the equivalent deformation that took place in the $\mathrm{Mg}-\mathrm{Li}$ and aluminum MMC sheets. The thickness of each layer is approximately $0.33 \mathrm{~mm}(330 \mu \mathrm{m})$ indicating that a reduction of about ten to one took place in this region. The Mg- $\mathrm{Li}$ layers show elongated light-colored $\alpha$ grains in a matrix of $\beta$ grains. The aluminum MMC layers have a mottled two-phase structure. A sharp boundary appears to exist between the layers. An interface reaction 
layer is present, however, but it is not obvious at this magnification.

Fig. 4 illustrates the influence of pressing rate on the resulting microstructure of the laminate at a sufficiently high magnification to show the interface reaction layer. The light colored $\alpha$ phase in the $\mathrm{Mg}-9 \% \mathrm{Li}$ layer is seen to have a coarser and less elongated structure at the slow pressing rate compared to the fast pressing rate. Clearly the long time involved in slow pressing allowed for coarsening of the $\alpha$ phase. On the edge of the $\mathrm{Mg}-9 \% \mathrm{Li}$ layers there is a continuous film of $\alpha$. The presence of this continuous film (thicker in the slow pressing than in the fast pressing laminate) is caused by the diffusion of lithium in the original $\beta$ phase into the aluminum MMC layer, converting the $\beta$ phase into $\alpha$ phase. The $\beta$ phase is less stable than the $\alpha$ phase because atom motion is faster in the open bcc $\beta$ structure than in the hcp $\alpha$ structure. Furthermore, lithium is expected to be more mobile than magnesium because it is lighter and has a lower melting point. The dark layer adjoining the continuous film of $\alpha$, on the MMC side, is aluminum containing lithium. Within this layer fine precipitates of AlLi (or $\left.\mathrm{MgLiAl}_{2}\right)^{[6]}$ 
are visible. The SiC particles remain uniformly distributed in the aluminum MMC layers irrespective of the amount of deformation and time at temperature of pressing. This is because the aluminum matrix flows around the undeformable SiC particles during plastic flow at $450^{\circ} \mathrm{C}$.

Mechanical Properties

Fig. 5 shows the engineering stress-engineering strain curves at room temperature for the laminated composite as well as for the component materials. The initial strain rate of the tests was $10^{-4}$ $\mathrm{s}^{-1}$. All tests were performed at constant cross-head speed. The most important result obtained from these tests is that lamination of the aluminum MMC material with the $\mathrm{Mg}-9 \% \mathrm{Li}$ alloy led to considerable enhancement in the tensile ductility of the aluminum MMC. Whereas only $3.5 \%$ elongation was obtained in the aluminum MMC material, the laminated composite had $11.5 \%$ elongation. The enhanced ductility of the aluminum MMC material by lamination is related to the inhibition of necking in the MMC layers by the adjoining $\mathrm{Mg}-9 \% \mathrm{Li}$ layers. The resulting plastic flow in the MMC layers causes strain hardening to be observed in the laminated composite (Fig. 5), ultimately leading to fracture when the fracture 
strength of the composite was reached. The Mg-9\%Li alloy shows high tensile ductility (28\%) as observed in Fig. 5 with no strain hardening observed during plastic flow; the decrease in the engineering stress with deformation is related to a decrease in the cross-sectional area of the sample. When the $\mathrm{Mg}-9 \% \mathrm{Li}$ alloy data is plotted as true stress versus true strain, the curve is virtually flat indicating no strain-hardening.

As anticipated, the yield strength of the laminated composite (136 MPa) is between the yield strengths of the aluminum MMC (265 $\mathrm{MPa}$ ) and the $\mathrm{Mg}-9 \% \mathrm{Li}$ alloy (85 $\mathrm{MPa})$. The experimental yield strength of the laminated composite was compared with the prediction from the rule-of-averages as done earlier with other metal laminated composites[7]. The rule-of-averages is given by the following relation:

$$
\sigma_{y}=f_{A}\left(\sigma_{y}\right)_{A}+f_{B}\left(\sigma_{y}\right)_{B}
$$

where $\sigma_{y}$ is the tensile yield strength of the composite, $f_{A}\left(\sigma_{y}\right)_{A}$ is the volume fraction times the yield strength of one component, and $f_{B}\left(\sigma_{y}\right)_{B}$ is the volume fraction times the yield strength of the other component of the composite. This relation can be particularized to 
a 50 volume percent laminated composite, where $f_{A}=f_{B}=0.5$. In this case, one can compare the yield strength of different laminated composite systems (containing $50 \%$ of each component) by normalizing by the yield strength of the strongest component. Assuming that $\left(\sigma_{\mathrm{y}}\right)_{\mathrm{A}}$ in Eq. (1) is the strongest component, one can rewrite this equation as:

$$
\sigma_{y} /\left(\sigma_{y}\right)_{A}=0.5+0.5\left(\sigma_{y}\right)_{B} /\left(\sigma_{y}\right)_{A}
$$

Fig. 6 shows the application of Eq. (2) for predicting the normalized strength of the laminate as a function of the yield strength ratio of the component materials. The relation predicts a straight line. Also shown are experimental data for metal-base laminated composites consisting of equal volume fractions of the two components[2,7-9]. The laminates shown in Fig. 6 have a wide range in relative strengths - from systems in which there is a large difference in strength (such as ultrahigh carbon steel (UHCS)/annealed 304 stainless steel and $6090-\mathrm{SiC}-25 \mathrm{p} / \mathrm{Mg}-9 \% \mathrm{Li}$ ) to systems in which the yield strengths are very similar (such as UHCS/warm-rolled 304 stainless steel). As can be seen, the data for the UHCS laminated composites mostly fit in very well with the predicted line. No interdiffusion occurred in the UHCS laminated 
composites. In one exception, however, for UHCS/Fe-3\%Si, the data point lies above the predicted line. On the other hand, the present Al-MMC/Mg-9\% Li laminate, as well as other Al MMC laminates, fall below the predicted line. These deviations from the predicted line are clearly not influenced by relative strength differences between the component layers, since experimental values at low strength ratio show agreement comparable to values at high strength ratio. It is believed that deviations from the straight line behavior are probably a result of interlayer reactions during laminate preparation, whose presence can contribute to an increase or decrease in strength. In the case of the three different Al MMC laminates investigated, it is concluded that the interlayer region created during processing is weak in contrast to the strong component making up the laminate. The interlayer is clearly visible in the case of the present $\mathrm{Al} \mathrm{MMC} / \mathrm{Mg}-9 \% \mathrm{Li}$ laminate, but is not readily evident in the two Al MMCs laminated with Al 5182[2,9]. The absence of a visible interlayer region in the latter cases is because magnesium diffusion occurs from Al 5182 to the Al MMC layer. This leads to an interlayer region depleted of magnesium in the Al 5182 which is weaker than the undepleted region. No visible interlayer region is expected since magnesium remains dissolved in the aluminum matrix. 
Similarly, the tensile ductility of the Al $6090-\mathrm{SiC}-25 \mathrm{p} \mathrm{MMC/Mg-}$ 9\% Li laminated composite falls below the rule-of-averages. The predicted tensile ductility is $16 \%$ whereas the actual ductility is $11.5 \%$ (Fig. 5). The lack of agreement is not surprising. It has been shown previously that tensile ductility is a function not only of component properties but also of the interlayer boundary region. This interlayer boundary region can be influenced by processing conditions and heat treatment and can be detrimental to achieving optimal ductility[7, 10]. On an optimistic note, however, it has been shown that the tensile ductility of a metal laminated composite can be enhanced by decreasing the thickness of individual layers. Thus, in an UHCS-brass laminated composite, it was shown that the tensile ductility increases with decreasing layer thickness[3]. When the layer thickness was $750 \mu \mathrm{m}$, the tensile elongation was $13 \%$; with a layer thickness of $200 \mu \mathrm{m}$ the tensile elongation increased to $21 \%$, and at a layer thickness of $50 \mu \mathrm{m}$, the tensile elongation increased to $60 \%$. Thus, in this system, the tensile ductility of laminates approaches the ductility of the ductile component (brass in this case) when the layer thickness was $50 \mu \mathrm{m}$. It is clear that 
the layer thickness effect is so significant that values of ductility can be obtained that are below and above the rule-of-averages.

The Al-MMC/Mg-9\%Li laminated composite studied in this investigation has layer thicknesses which are in the order of $\mathbf{3 3 0}$ $\mu \mathrm{m}$. Based on the UHCS-brass study, it can be predicted that the tensile ductility of the present laminated composite can be improved considerably by a reduction in layer thickness. Furthermore, minimizing the amount of interdiffusion during laminate preparation should also contribute favorably to enhancing the tensile ductility. An additional factor to consider is control of the grain size in the $\mathrm{Mg}-9 \% \mathrm{Li}$ material. Investigations have shown that, when the grain size is fine, the room temperature ductility of the Mg-9\%Li alloy is increased, with tensile elongations in the order of 60 to $70 \%$ obtained[11, 12], rather than $28 \%$ elongation in the present material. Such enhanced ductility in the Mg-9\%Li material should contribute to enhancing the ductility of the Al-MMC/Mg-9\%Li laminated composite. 
Fracture Behavior

Fractographic analyses of the fractured samples were conducted. Fig. 7 shows the fracture surface of the Al $6090 / \mathrm{SiC} / 25 p \mathrm{MMC}$ material tested by itself (Fig. 7a) and in laminated form (Fig. 7b). The fracture surface in the Al MMC material when tested by itself shows cracked SiC particles, whereas in the laminate the Al-MMC material shows virtually no cracked particles. The Al MMC material in the laminate also showed a much higher frequency of dimples than the Al MMC material when tested by itself. It is proposed that the influence of lamination is to postpone void initiation because necking is delayed (and the associated hydrostatic tensile stress build-up is also delayed). This allows for a large strain before fracture is initiated. This large plastic strain contributes to the initiation of many small voids which at the point of failure creates the numerous small dimples observed.

\section{CONCLUSIONS}

An aluminum MMC $6090 / \mathrm{SiC} / 25 \mathrm{p}$ has been laminated with an equal amount of a $\mathrm{Mg}-9 \% \mathrm{Li}$ alloy by a press bonding technique resulting in an average layer thickness of $330 \mu \mathrm{m}$. The tensile 
properties, including ductility, were evaluated and the following conclusions were reached:

1. Lamination of the aluminum MMC with $\mathrm{Mg}-9 \% \mathrm{Li}$ alloy enhances the tensile ductility of the AI MMC from $3.5 \%$ to $11.5 \%$ elongation.

2. The enhanced ductility by lamination was achieved by the inhibition of necking of the aluminum MMC layers by the adjoining $\mathrm{Mg}-9 \% \mathrm{Li}$ layers.

3. The tensile yield strength of the aluminum MMC laminated composite is below the yield strength predicted by the rule-ofaverages as a result of interlayer reaction products.

4. Analysis of the other laminated metal composites, including some based on ultrahigh carbon steel (UHCS), shows that the yield strength of UHCS laminates tend to follow the rule-of-averages behavior, whereas laminates based on aluminum MMC fall below the rule-of-averages; these differences in results are attributed to the absence of interlayer reaction regions in the UHCS laminated composites. 
5. It is predicted that the tensile ductility of the aluminum $\mathrm{MMC} / \mathrm{Mg}-9 \% \mathrm{Li}$ laminate will be improved by decreasing the layer thickness and by decreasing the grain size in the Mg-9\% Li layers.

\section{ACKNOWLEDGMENT}

- The authors thank Dr. A. P. Divecha, Naval Surface Warfare Center, White Oak, Maryland, who provided the Mg-9\% Li castings and Dr. Kevin Brown, Kaiser Aluminum, Center for Technology, Pleasanton, California, who provided Al 5182 sheets. Assistance by Ralph Otto for making laminates, Chris Steffani for descaling materials, Will Andrade and Gene Stebbins for machining, Reynold Lum and Al Shields for testing, and Jim Ferreira for metallography are also appreciated. 


\section{REFERENCES}

1. W. C. Harrigan, Jr., JOM 43(8), 32-35, 1991

2. C. K. Syn, D. R. Lesuer and O. D. Sherby, Proc. Int'I Symp. on Light Materials for Transportation Systems, N. J. Kim., ed., Kyongju, Korea, June 20-23, 1993, pp. 763-771.

3. C. K. Syn, D. R. Lesuer, J. Wolfenstine and O. D. Sherby, Met. Trans. A, 24A, 1647-1653, 1993.

4. G. Gonzalez-Doncel and O. D. Sherby, Acta Met. et Mater., 41, 2797-2805, 1993.

5. O. A. Kaibyshev, Superplasticity in Commercial Alloys, Metallurgiya, Moscow, 1984.

6. D. W. Levinson and D. J. McPherson, Trans. ASM, 48, 689-705, 1956.

7. S. Lee, J. Wadsworth and O. D. Sherby, J. Composite Materials, 25, 842-853, 1991.

8. O. D. Sherby, S. Lee, R. Koch, T. Sumi and J. Wolfenstine, Materials and Manufacturing Processes, 5, 363-376, 1990.

9. C. K. Syn, D. R. Lesuer and O. D. Sherby, Proc. 1st Int'I Conf. Advanced Synthesis of Engineered Materials, J. J. Moore, E. J. Lavernia and F. H. Froes, eds., San Francisco, August 31-September 2, 1992, pp. 149-156.

10. K. K. Chawla, Interfaces in Metal Ceramics Composites, R. Y. Lin, R. J. Arsenault, G. P. Martins, and S. G. Fisherman, eds., TMS, Warrendale, PA, 1990, pp. 541549.

11. E. M. Taleff, O. A. Ruano, J. Wolfenstine and O. D. Sherby, J. Mater. Res., 7, 2131$2135,1992$.

12. K. Higashi, A. Aoki, K. Kuboda and S. Tanimura, Aspects of High Temperature Deformation and Fracture in Crystalline Materials, Y. Hoshi, H. Yoshinaga, H. Oikura and K. Maruyama, eds., Proc. 7th JIM Int'I Symposium, Nagoya, Japan, 2831 July 1993, The Japan Institute of Metals, pp. 479-486. 
Figure captions

Fig. 1. Schematic illustration of the stacking of aluminum MMC and Mg-9\%Li alloy sheets for preparation of the laminated metal composite consisting of $6090 / \mathrm{SiC} / 25 \mathrm{p} \mathrm{MMC}$ and Mg-9\%Li alloy. A cross-sectional view (a) along the section AA of the assembly (b)shows a Mg-9\%L disc framed by an Al 5182 ring.

Fig. 2. Photograph of a section of the pressed laminated metal composite showing the uniform thickness of individual 6090/SiC/25p MMC and Mg-9\%Li alloy layers in the center of pressing.

Fig. 3. Low magnification photomicrograph showing the uniform thicknesses achieved in the pressed 6090/SiC/25p and Mg-9\%Li alloy laminate. The Al MMC layers show a mottled appearance whereas the Mg-9\%Li alloy layers show elongated $\alpha$ grains (of the light contrast) in the matrix of $\beta$ (of the dark contrast).

Fig. 4. High magnification photomicrographs showing the interface reaction region in the 6090-SiC-25p/ Mg-9\%Li alloy laminate after slow pressing (a) and fast pressing (b).

Fig. 5. Engineering stress - engineering strain curves for the $6090-\mathrm{SiC}-25 \mathrm{p} / \mathrm{Mg}-$ 9\% L alloy laminate composite and for the component materials.

Fig. 6. Experimentally measured yield strength of laminated metal composites containing fifty percent of each component, compared with prediction based on the rule-of-averages.

Fig. 7. Fractographs of the aluminum MMC material tested by itself (a) and in laminated form (b). 


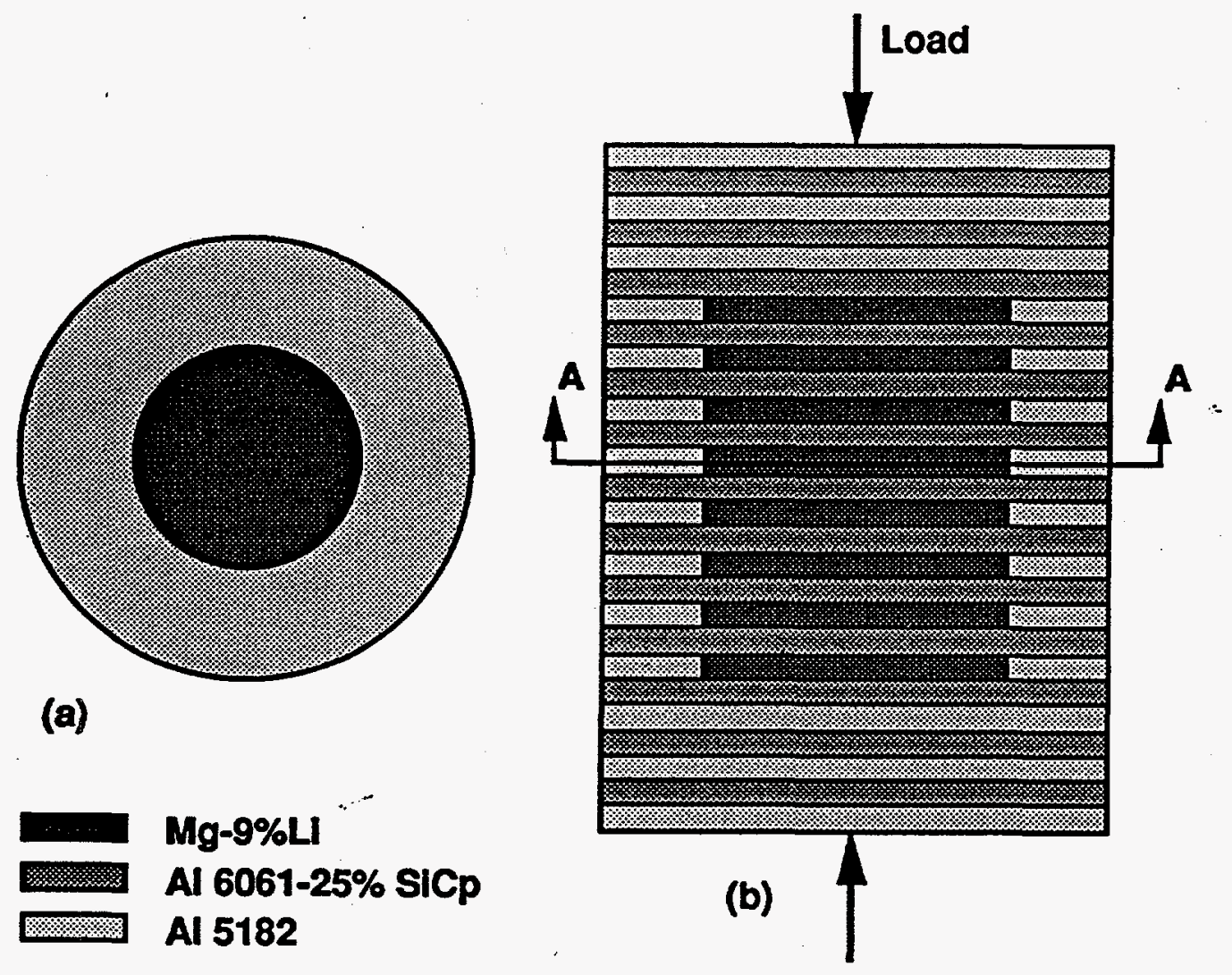

Fig. 1. Schematic illustration of the stacking of aluminum MMC and $\mathrm{Mg}-9 \% \mathrm{Li}$ alloy sheets for preparation of the laminated metal composite consisting of 6090/SiC/25p MMC and Mg-9\%Li alloy. A cross-sectional view (a) along the section AA of the assembly (b)shows a Mg-9\%Li disc framed by an Al 5182 ring. 


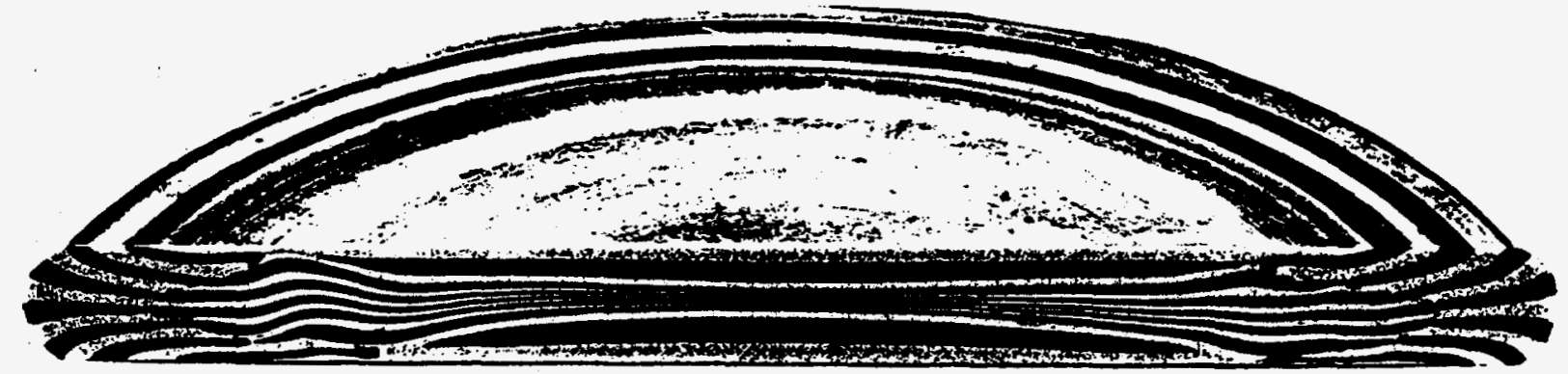

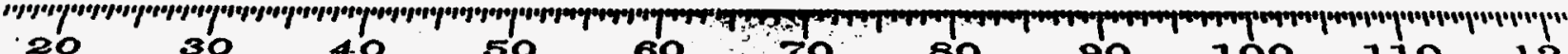
20
$1,1,11,1,11,1,11,1,11,1,11,1,11,1,11,1,1,1,1,1,1,11,1,1,1,11,1,11,1,11,1,11,1,11,1,11,1,11,1,11,1,11,1$

Fig. 2. Photograph of a section of the pressed laminated metal composite showing the uniform thickness of individual 6090/SiC/25p MMC and Mg-9\%Li alloy layers in the center of pressing. 


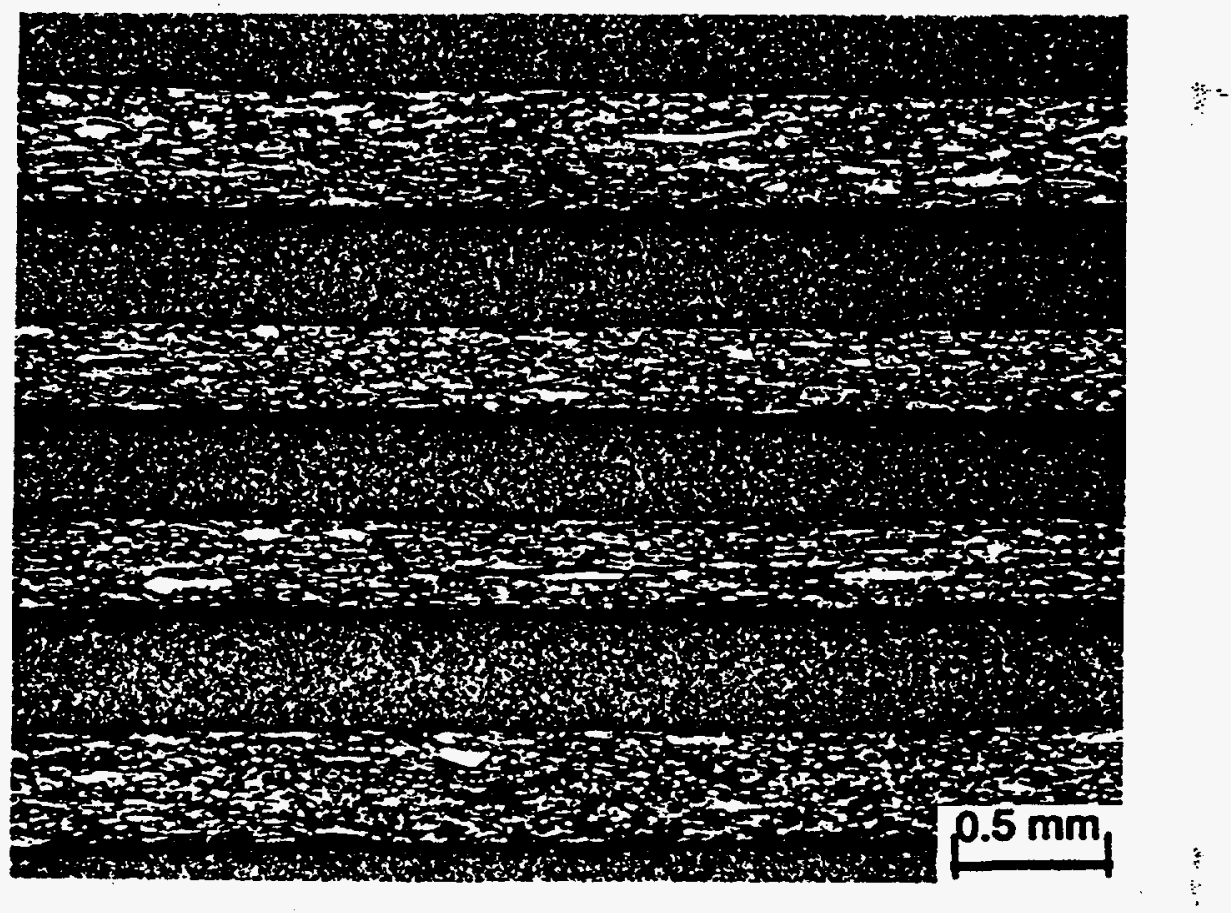

Fig. 3. Low magnification photomicrograph showing the uniform thicknesses achieved in the pressed 6090/SiC/25p and Mg-9\%Li alloy laminate. The Al MMC layers show a mottled appearance whereas the Mg-9\% $\mathrm{Li}$ alloy layers show; elongated $\alpha$ grains (of the light contrast) in the matrix of $\beta$ (of the dark contrast). 


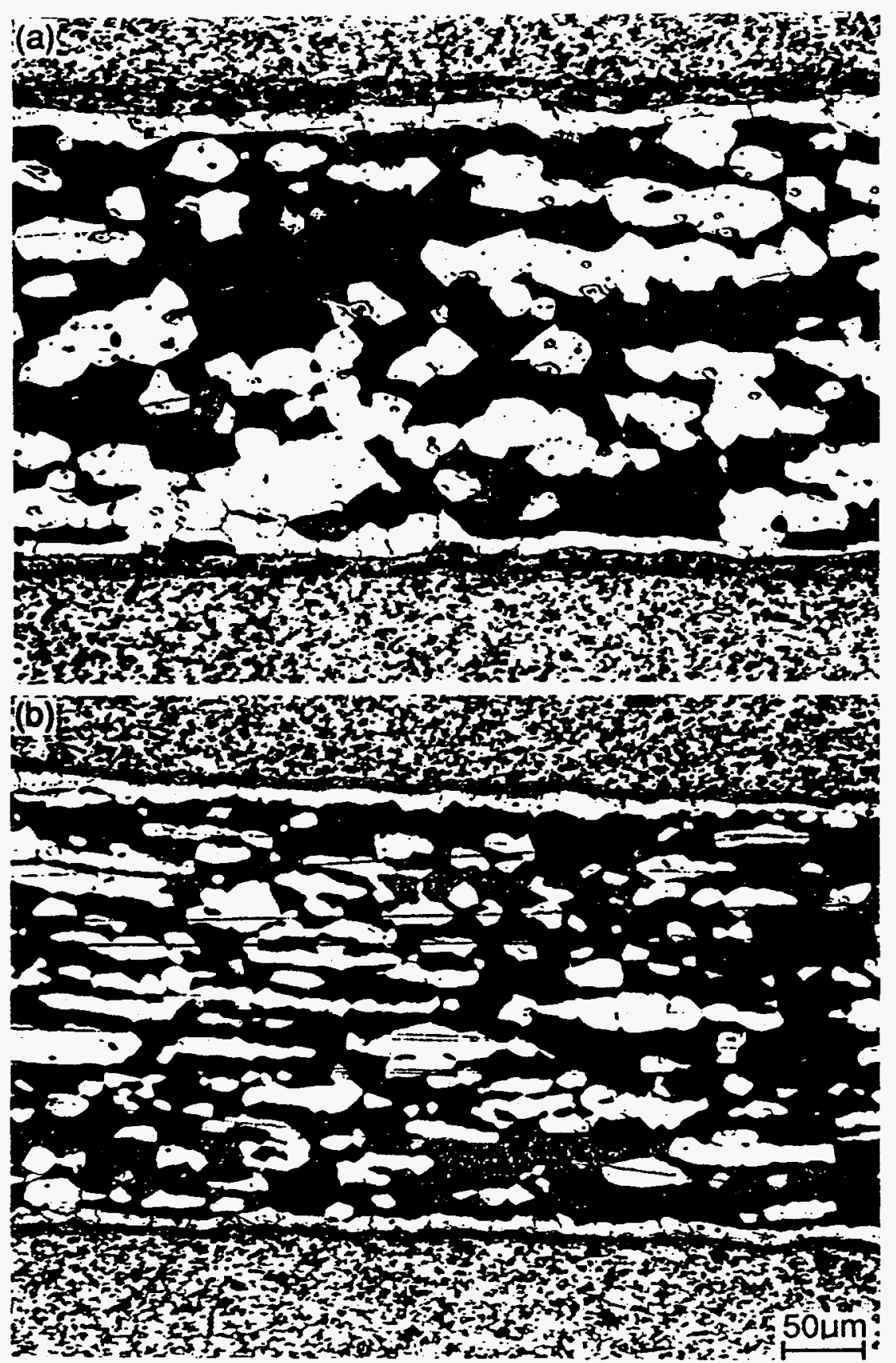

Fig. 4. High magnification photomicrographs showing the interface reaction region in the 6090-SiC-25p/ Mg-9\%Li alloy laminate after slow pressing (a) and fast pressing (b). 


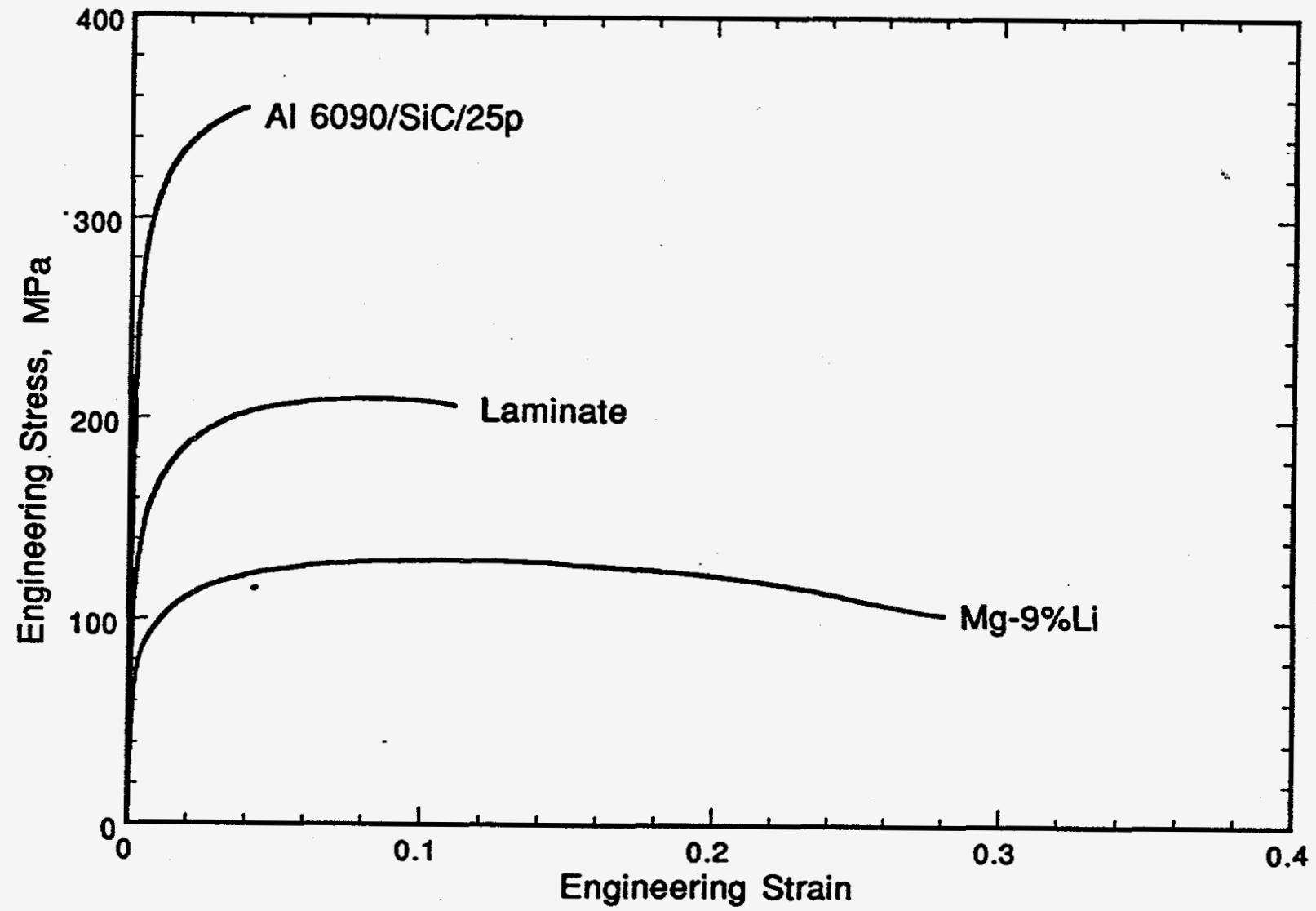

Fig. 5. Engineering stress - engineering strain curves for the $6090-\mathrm{SiC}-25 \mathrm{p} / \mathrm{Mg}$ 9\%L alloy laminate composite and for the component materials. 


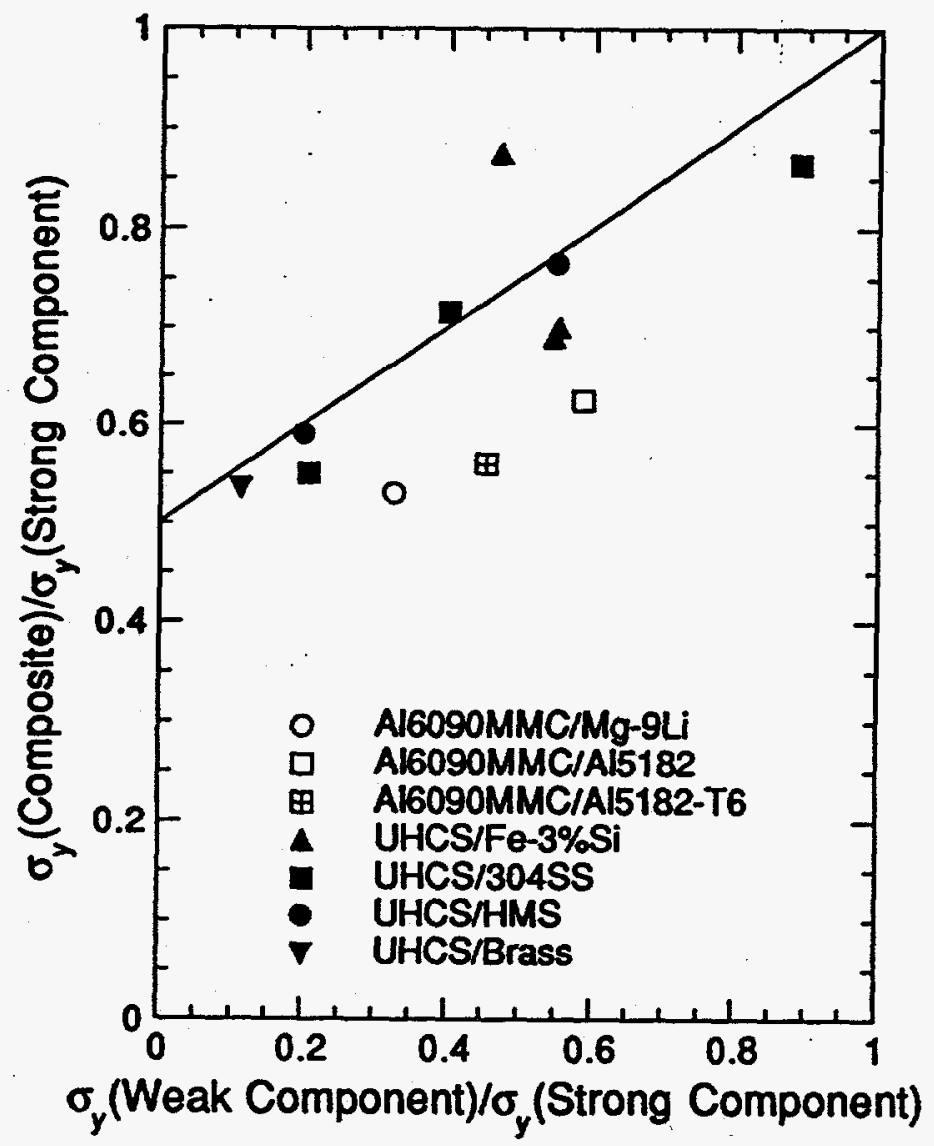

Fig. 6. Experimentally measured yield strength of laminated metal composites containing fifty percent of each component, compared with prediction based on the rule-of-averages. 

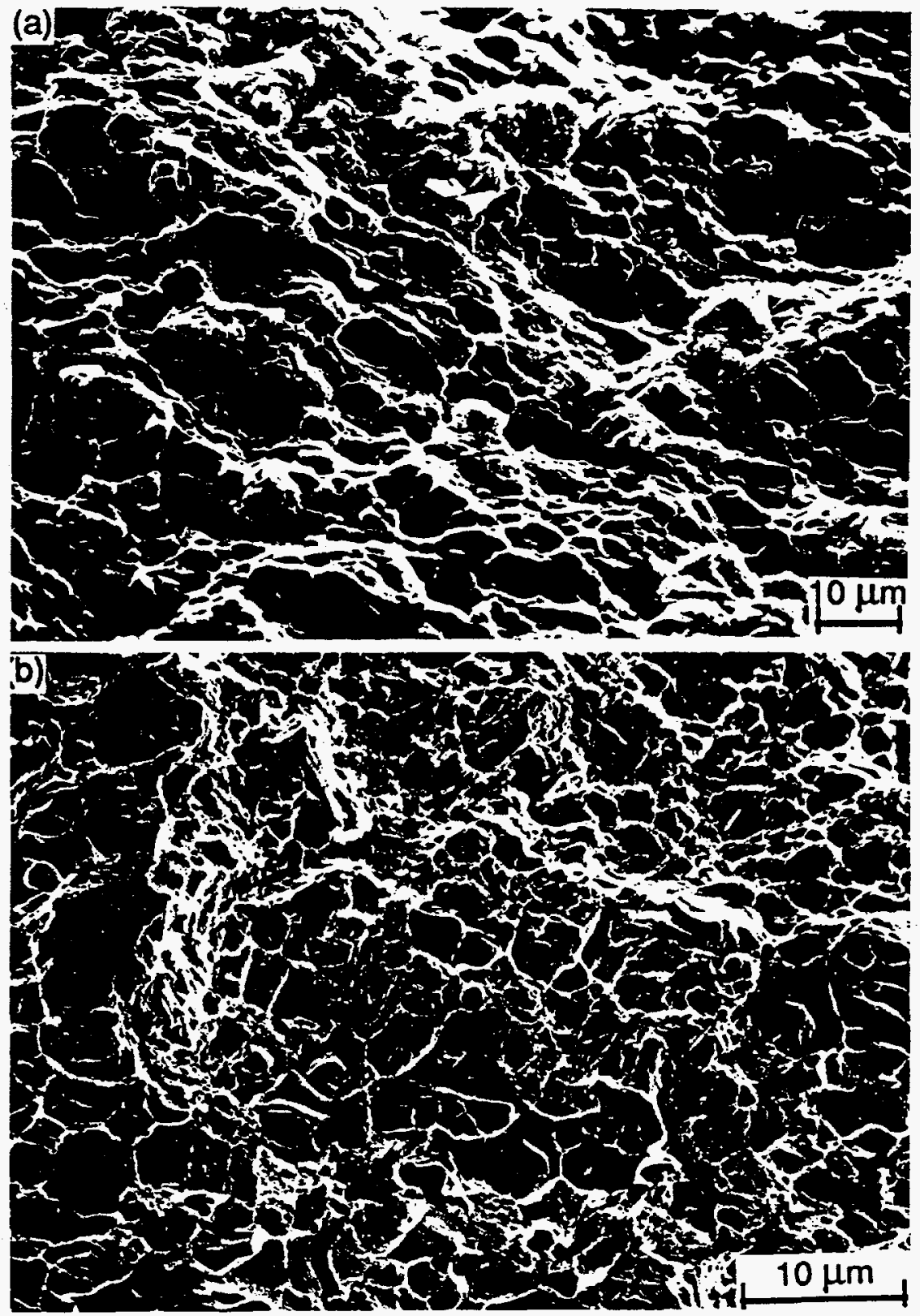

Fig. 7. Fractographs of the aluminum MMC material tested by itself (a) and in laminated form (b). 